\section{Black hairy tongue: What is your call?}

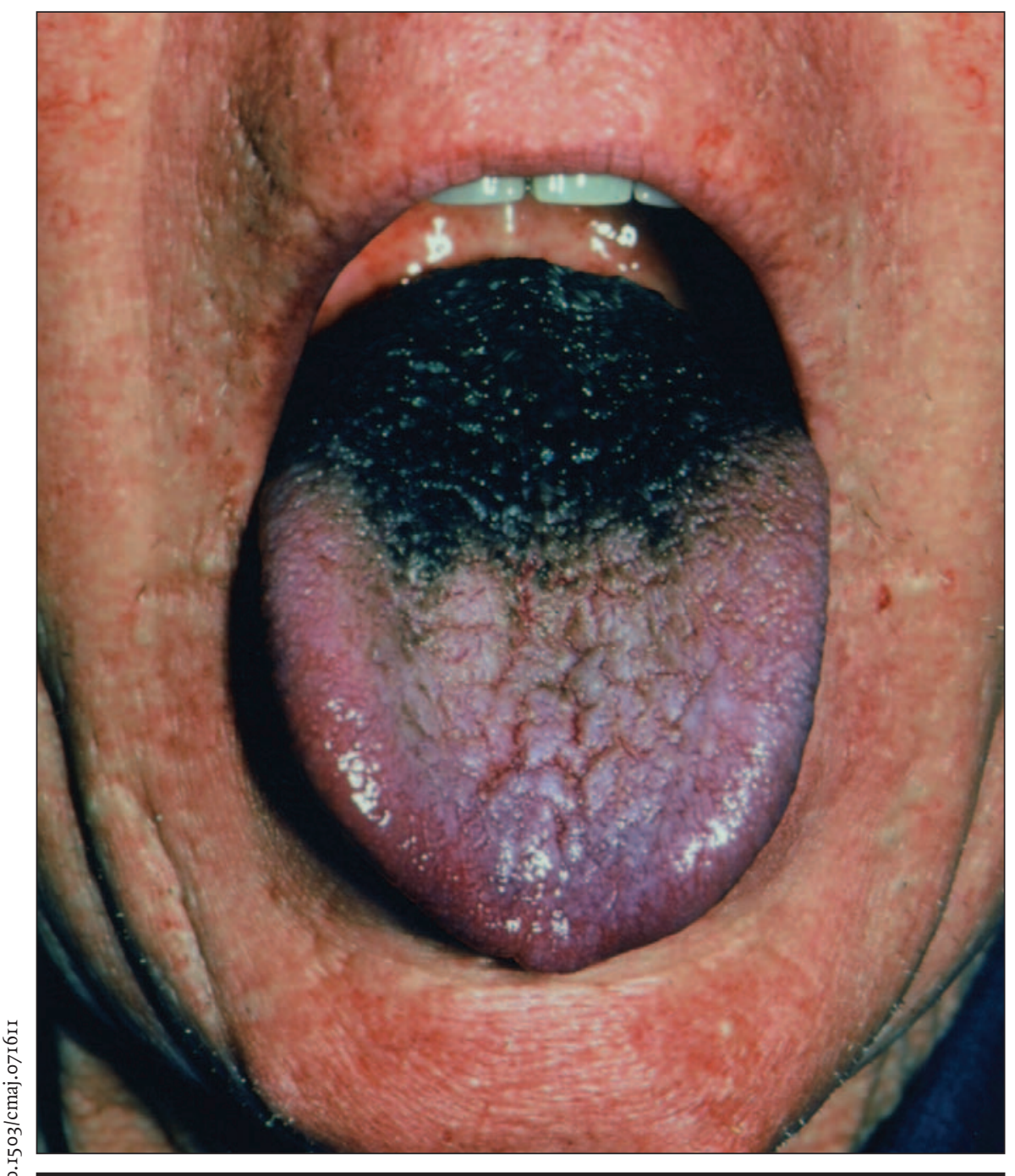

Figure 1: Black discoloured tongue of a 73-year-old man.
A 73-year-old male smoker attended a follow-up outpatient clinic I8 months after starting antibiotic therapy (rifampicin, isoniazid and clarithromycin) for a nontuberculous mycobacterial lung infection. His infection was clinically improving, but the patient had noticed that his tongue had become discoloured over the previous 4 weeks. Aside from the black discoloration, the patient's tongue was asymptomatic (Figure I). The results of microbiologic and histologic tests of swabs from his tongue were negative for infective and malignant conditions. An otolaryngologist advised the patient to wash his tongue twice daily with a soft toothbrush. The colour of his tongue returned to normal over the next 3 weeks, and the condition did not recur.

\section{What is your diagnosis?}

a. Stained normal tongue

b. Oral hairy leukoplakia

c. Pigmented fungiform papillae of the tongue

d. Lingua villosa nigra

e. Acanthosis nigricans 


\section{CLINICAL QUIZ}

\section{Discussion}

The answer is (d) lingua villosa nigra (also known as black hairy tongue). This condition is benign and selflimiting, ${ }^{1}$ and is characterized by an abnormal black coating on the tongue's dorsal surface just anterior to the circumvallate papillae. Brown, yellow and green discoloration has also been described. The sides and tip of the tongue are rarely involved. Lingua villosa nigra is caused by defective desquamation of the tongue with elongation (up to I $8 \mathrm{~mm}$ in length) and hypertrophy of the filiform papillae. ${ }^{2}$

The exact pathogenesis is unclear, but it is generally thought that an abnormality in the filiform papillae prevents normal débridement and cleaning of the tongue, which allows debris to accumulate and bacteria (and sometimes yeast) to overgrow. These microorganisims synthesize porphyrins, which may contribute to the discoloration. In some cases, overgrowth of Candida albicans can lead to a painful burning (glossopyrosis), which requires topical antifungal therapy.

Precipitating factors include smoking, alcohol, dehydration, use of topical or systemic antibiotics, hyposalivation, trigeminal neuralgia, poor oral hygiene and cranial radiation therapy. Lingua villosa nigra is usually asymptomatic, and physician visits are usually because of aesthetic anxiety. However, symptoms may include halitosis, metallic taste, tickling sensation and, in severe cases, gagging. ${ }^{1}$ Estimates of prevalence range from $0.15 \%$ to $\mathrm{II} \%$, depending on the population. ${ }^{3,4}$ It is well accepted, however, that the incidence and prevalence increase with age, ${ }^{3}$ probably because of the cumulative lifetime effects of drinking coffee and smoking.

Differential diagnosis: The differential diagnosis includes a normal tongue that has been stained black by food colourings or bismuth ingestion, oral hairy leukoplakia, pigmented fungiform papillae of the tongue and acanthosis nigricans (Table I). Oral hairy leukoplakia occurs most often in men

\begin{tabular}{|c|c|}
\hline Diagnosis & Characteristics \\
\hline $\begin{array}{l}\text { Stained normal } \\
\text { tongue }\end{array}$ & $\begin{array}{l}\text { - Normal tongue stained after food colouring or bismuth } \\
\text { ingestion } \\
\text { - Does not appear hairy } \\
\text { - Prompt return to normal with cleaning }\end{array}$ \\
\hline $\begin{array}{l}\text { Oral hairy } \\
\text { leukoplakia }\end{array}$ & $\begin{array}{l}\text { - Tongue appears hairy with white lesions } \\
\text { - Occurs most commonly in immunocompromised patients } \\
\text { - May involve the dorsal and ventral tongue surfaces, } \\
\text { the buccal mucosa and the gingiva }\end{array}$ \\
\hline $\begin{array}{l}\text { Pigmented } \\
\text { fungiform papillae } \\
\text { of the tongue }\end{array}$ & $\begin{array}{l}\text { - Rare (people with dark complexions more commonly } \\
\text { affected than those with light complexions) } \\
\text { - Enlarged fungiform (not filliform) papillae } \\
\text { - Lateral aspects and apex of tongue are more involved than } \\
\text { the dorsum } \\
\text { - Lesions are not very confluent }\end{array}$ \\
\hline Lingua villosa nigra & $\begin{array}{l}\text { - Tongue appears hairy and black (other colours may } \\
\text { also occur) } \\
\text { - Rarely involves the side or tip of the tongue } \\
\text { - Patients may report symptoms such as burning or gagging }\end{array}$ \\
\hline $\begin{array}{l}\text { Acanthosis } \\
\text { nigricans }\end{array}$ & $\begin{array}{l}\text { - Multiple small brown or black fine papillary lesions } \\
\text { - Lips are usually involved } \\
\text { - Often associated with underlying malignant disease }\end{array}$ \\
\hline
\end{tabular}

who are HIV positive and smoke, and it may involve the ventral and dorsal surfaces of the tongue as well as the gingivae and buccal mucosa. White coloured plaques give the tongue a hairy appearance, which can appear and disappear spontaneously. Pigmented fungiform papillae of the tongue is a benign condition that affects dark-skinned people. The fungiform papillae, which exist primarily at the apex and lateral surfaces of the tongue, become enlarged and hyperpigmented, taking on a dark appearance because of melanin-laden macrophages. Acanthosis nigricans is often associated with malignancy. There is elongation of the filliform papillae on the dorsal and lateral aspects of the tongue that appear as multiple papules that are rarely pigmented, and the lips are usually involved.

Although lingua villosa nigra may resolve spontaneously, patients are recommended to avoid precipitating factors. Treatment usually involves gentle cleaning of the tongue with a soft toothbrush. ${ }^{1}$ Pharmacologic interventions are rarely required, ${ }^{5}$ although in more severe cases, antifungals, retinoids or mouthwashes may be used. If other treatments fail, the papil- lae can be clipped or removed using techniques such as carbon dioxide laser burning and electrodesiccation.

\section{Emmet E. McGrath MB \\ Philip Bardsley MD}

Gurnan Basran MD

Respiratory Medicine

Rotherham District General Hospital United Kingdom

Competing interests: None declared.

\section{REFERENCES}

I. Sarti GM, Haddy RI, Schaffer D, et al. Black hairy tongue. Am Fam Physician 1990;41:1751-5.

2. Prinz H. Black tongue. Br Dent J I925;46:1265-74

3. Farman AG. Hairy tongue (lingua villosa). J Oral Med I977;32:85-9I

4. Avcu N, Kanli A. The prevalence of tongue lesions in 5150 Turkish dental outpatients. Oral Dis 2003;9:188-95.

5. Tamam L, Annagur BB. Black hairy tongue associated with olanzapine treatment: a case report. $M t$ Sinai J Med 2006;73:89I-4.

CMAJ invites contributions to the Clinical Quiz column, which uses multiple-choice questions to guide a focused image-based discussion of the diagnosis or management of clinical cases. Submit manuscripts online at http://mc.manuscriptcentral.com/cmaj. 